7. Weibel ER. Morphometry of the human lung. Berlin, Springer-Verlag, 1963.

8. Thurlbeck WM. The internal surface area of nonemphysematous lungs. Am Rev Respir Dis 1967; 95: 765-773.

9. Gundersen HJG, Bagger P, Bendtsen TF, et al. The new stereological tools: disector, fractionator, nucleator and point sampled intercepts and their use in pathological research and diagnosis. APMIS 1988; 96: 857-881.

10. Cruz-Orive LM, Weibel ER. Recent stereological methods for cell biology: a brief survey. Am J Physiol 1990; 258: L148-L156.

11. Bolender RP, Hyde DM, Dehoff RT. Lung morphometry: a new generation of tools and experiments for organ, tissue, cell, and molecular biology. Am J Physiol 1993; 265: L521L548.

12. Ochs M, Nyengaard JR, Jung A, et al. The number of alveoli in the human lung. Am J Respir Crit Care Med 2004; 169: $120-124$

\section{From the authors:}

H. Fehrenbach is perfectly correct to point out that the assessment of our data is based only on the measurement of mean chord length ( $\mathrm{Lm})$ and lung volume estimations, whereas "a whole range of stereological tools is available for more detailed anaysis". However, the results were so dramatic that we felt that there was no need for these further, rather esoteric analyses, which would not necessarily have provided any further useful information for understanding the biology of the system. The results were also so clear-cut that errors due to tissue shrinkage (all samples were processed at the same time so this error should be equal anyway) or including the occasional alveolar duct in our computer-based measurements of alveolar Lm (800 measurements per field of view, 30 fields of view per Lm score) were also likely to be insignificant.
It is not these stereological debates that are the source of the controversies about whether or not retinoic acid (RA) induces alveolar regeneration, since the initial positive report by MASSARO and MASSARO [1]. We should instead be concerning ourselves with other biological reasons, such as the extent of initial damage, methods of delivery of RA, the phamacokinetics of RA, times after dosing, age of the animals etc., as potential causes for these glaringly opposite reports of "RA induces alveolar regeneration" versus "RA does not induce alveolar regeneration".

Nevertheless, it must be acknowledged, as we do in our paper and as the editorial does, that the most important feature of these regenerated lungs is to determine whether they can or cannot take up oxygen efficiently, that is, whether they are fully functional. This is the missing piece of evidence in these and other experiments determining the forced expiratory volume in one second of the mouse or devising a mini-mouse exercise test. However, it would be very surprising if animals had evolved developmental and regenerative mechanisms that resulted in structurally sound but nonfunctional organs. In the words of the playwrite "A" stands for absolutely (perhaps).

M. Maden*, M. Hind ${ }^{\#}$

*MRC Centre for Developmental Neurobiology, King's College London, and ${ }^{\#}$ Royal Brompton Hospital, London, UK.

\section{References}

1. Massaro GD, Massaro D. Retinoic acid treatment abrogates elastase-induced pulmonary emphysema in rats. Nat Med 1997; 3: 675-677.

\title{
Pre- and post-bronchodilator spirometric values and the degree of reversibility in patients with COPD
}

\section{To the Editor:}

I thank P. Sterk for an interesting and informative Editorial on the definition and classification of patients with chronic obstructive pulmonary disease (COPD) [1]. However, I cannot help but get the feeling from reading the article that perhaps most, if not all, of the emphasis is placed on post-bronchodilator spirometric values. As pointed out by STERK [1], COPD is a disease where airflow limitation is not fully reversible. Taking this into account, one would intuitively expect that the definition and classification of COPD should at least be based on three criteria: namely, preand post-bronchodilator spirometric values, and the degree of reversibility between the two values; rather than depending solely on post-bronchodilator values. Would it not be meaningless to have just a post-bronchodilator value without its pre-bronchodilator counterpart, as significant reversibility wrongly diagnosed as fixed airflow limitation, as pointed out by STERK [1], may lead to potential over-diagnosis and overestimation of the severity of patients with COPD? It would perhaps be sensible if reporting of future articles relating to research on patients with COPD incorporated both the pre- and post-bronchodilator values, together with the degree of reversibility.

D.K.C. Lee

Dept of Respiratory Medicine, Ipswich Hospital, Ipswich, UK.

\section{References}

1. Sterk PJ. Let's not forget: the GOLD criteria for COPD are based on post-bronchodilator FEV1. Eur Respir J 2004; 23: 497-498.

\section{From the Editor:}

I appreciate D. Lee's comments regarding my editorial on the usage of postbronchodilator spirometry in the Global Initiative for Chronic Obstructive Lung Disease (GOLD) and American Thoracic Society/European Respiratory Society 